\title{
Effects of Salinity Variations on Acute Toxicity of Copper Sulphate against Oreochromis niloticus Fingerlings in Laboratory Bioassays
}

\author{
Osuala, Fidelia I. ${ }^{1}$ Bawa- Allah, Kafilat A. ${ }^{2}$ \\ ${ }^{1,2}$ (Department of zoology, university of Lagos, Akoka-Yaba, Lagos, Nigeria)
}

\begin{abstract}
The study was carried out to investigate the salinity tolerance and relative acute toxicity of copper sulphate $\left(\mathrm{CuSO}_{4}\right)$ under fresh water in varying salinity level, against Oreochromis niloticus fingerlings. A total of 280 fingerlings of $O$. niloticus (mean weight; $20 \pm 4$ g; 4-6 weeks old) were used as test animals in this study. The test compound used was copper as $\mathrm{CuSO}_{4} .5 \mathrm{H}_{2} \mathrm{O}$ analar grade (molecular weight $249.68 \mathrm{~g}$ ). The dose response data were analyzed by probit analysis. The results showed that on the basis of daily mortality assessment, $O$. niloticus were unable to survive in water with salinity above 22ppt within a $24 \mathrm{hr}$ period, but the fish survived well at lower salinities below 12ppt. Based on $96 \mathrm{hr} \mathrm{LC}_{50}$ values, toxicity of $\mathrm{CuSO}_{4}$ against the fingerlings increased with increase or decrease in salinity except at 12ppt where the toxicity was minimal. The significance of this study is in setting ecologically sound, safe limits that are relevant for the prevailing two hydrological seasons in the tropics for the discharge of heavy metals into lagoons and the advantages of breeding $O$. niloticus under typical brackish water conditions, instead of freshwater.
\end{abstract}

Keywords: Acute toxicity, Fingerlings, Copper sulphate, Oreochromis niloticus, Salinity

\section{Introduction}

All over the world including West Africa, there are lagoons off the coast lines that are characterized by brackish water at salinity between 1 and 35 parts per thousand and usually known to be productive, being rich in flora and fauna.

The Lagos lagoon is the largest among four others found along the West African coast (1). This lagoon covers about $700 \mathrm{~km}$ on the western coast of Nigeria $\left(6^{0}-26^{1} \mathrm{~N} ; 3^{0}-23^{1}-4^{0} 20^{1} \mathrm{E}\right)$. The Lagos lagoon is an abode for different types of organisms (2). Studies carried out in the middle of the last century showed that Lagos lagoon and others in West Africa had much wider variety of pelagic and benthic organisms than are indicated by studies carried out in the last two decades $(3,4)$.

The authors $(3,5)$ suggested that pollution of lagoon ecosystems by industrial wastes is one of the major reasons for the observed reduction in diversity and population densities of pelagic, benthic animals and plant species. These industrial wastes are complex admixtures of several classes of pollutants such as hydrocarbons, pesticides and heavy metals (6). The exact type and amount depends on the type of industry, technology adopted, raw materials used and waste treatment facilities.

Heavy metals are among the most common constituents of industrial effluents, hence this serves as a major source of these pollutants into the ecosystems. Heavy metals are elements with density greater than $5 \mathrm{gcm}^{3}$ and atomic number greater than that of calcium. They are important sources of pollution, toxic at relatively low concentrations, in most cases nondegradable and persistent in the environment long after the source of emission has been removed (7). Thus heavy metals can bioaccumulate in one or several compartments across foods webs as shown by several scientific observations $(8,9,10)$. Heavy metals are highly toxic to living organisms and their non degradable characteristic creates a highly significant environmental problem as the concentrations accumulate over time, whereas the toxicity persists in the ecosystems.

Copper is one of the most common heavy metals detected in the Lagos lagoon (3) and although it is useful in living systems, it becomes toxic at high enough concentrations. It is toxic to amphibians, benthic invertebrates, fishes found in the aquatic environment $(11,12)$.

In brackish water ecosystems, the major physicochemical parameter that varies widely in response to the two hydrological seasons (Wet and Dry) which characterize tropical regions is salinity. Due to this characteristic the lagoon is usually inhabited mainly by animals that can tolerate a wide range of salinity changes (euryhaline species). Variation of salinity in lagoon ecosystems in response to the two seasons influenced heavy metal toxicity and therefore the damage potential of metals in the field to biota (3)

The implications of this are that the extent of biological damage caused by pollutants may vary with salinity, which changes from dry season to wet season. More research is therefore justifiable along these lines, in which the responses of animal species typical of the Lagos lagoon, to heavy metals and other priority pollutants will be investigated under varying salinity conditions typical of local lagoon ecosystems. 
Oreochromis niloticus is among some of the edible commercial fish species that inhabit the Lagos lagoon and is also bred in commercial fish farms; it will therefore be of interest to study influence of salinity changes on the effect of pollutants like heavy metals against this edible species of fish that is ecologically important in the Lagos lagoon. O niloticus can be cultured in fresh water and this makes it easy to be cultured in the laboratory.

Several workers have investigated the acute toxicity of metals against organisms inhabiting the Lagos lagoon. Research has shown the acute toxicity of $\mathrm{CuSO}_{4}$ against 3 benthic species; Tympanotonus fuscatus, Clibanarius africanus and Sesarma hurzadi (13). The authors found out that $C$. africanus is the most susceptible with the $96 \mathrm{hr} \mathrm{Lc}{ }_{50}$ value of $4.342 \mathrm{mg} / \mathrm{l}$, followed by $T$ fuscatus and $S$ hurzadi being the most tolerant with a $96 \mathrm{hr}$ $\mathrm{Lc}_{50}$ value of $242.102 \mathrm{mg} / \mathrm{l}$. Physicochemical parameters prevailing in an aquatic ecosystem affects the toxicity of heavy metals. An organism living under optimal environmental condition is more resistant than one under stress (14). Salinity in the Lagos lagoon varies from $8.0-30.0 \mathrm{ppt}$ in the dry season to $0.0-17.9 \mathrm{ppt}$ in the wet season (3).

The effect of this changing salinity on toxicity of some of the heavy metals that characterize the Lagos lagoon has been studied $(3,15)$. The authors reported that salinity influenced the toxicity of heavy metals and therefore the risk of harm to living organisms. For example, the toxicity of either $\mathrm{Cu}$ or $\mathrm{Hg}$ against three test organisms (Tilapia guinensis, Clibanarius africanus and Nerita senegalesis) was minimal at intermediate or typical brackish water salinity between $10-20 \mathrm{ppt}$, but metal toxicity increased significantly with increasing salinity, especially above $25 \mathrm{ppt}$ and decreasing salinity, particularly below 5 ppt. Based on 96 hr Lc c $_{50}$ values computed at varying salinities, it was found that the toxicities of $\mathrm{Cu}$ or $\mathrm{Hg}$ increased by as much as 1.5-2.8, 1.43, 2.5-5 times for $\mathrm{Cu}$; 1.8-13, 1.9-2.8, 1.6-3.2 times for $\mathrm{Hg}$ against $T$. guinensis, C. africanus and N. senegalesis respectively at salinities above $25 \mathrm{ppt}$ or below $5 \mathrm{ppt}$ when compared to the toxicity of equivalent metals at 15 ppt (3). Although there are other physichochemical parameters such Electrical conductivity (EC) and Total Dissolved Solids (TDS) that may also influence toxicity of metals in brackish ecosystems (16).

The influence of $\mathrm{P}^{\mathrm{H}}$ and salinity in brackish water on toxicity of four common heavy metals in the sediment of the estuarine clam, Ruditepes philippinarum (17). The authors studied this at different values of $\mathrm{P}^{\mathrm{H}}$ 6.5,7.5 and 8.5 and salinity 10,20 , and $30 \mathrm{ppt}$ and reported that the acute toxicity of the metals increased with decrease in values of both variables, being maximum at the lowest values $\left(\mathrm{P}^{\mathrm{H}}=6.5\right.$ and salinity=10 ppt).

The aim of this study is to determine salinity tolerance of $O$. niloticus fingerlings and to determine the relative acute toxicity of $\mathrm{CuSO}_{4}$ under fresh water and varying salinity level, against $\mathrm{O}$. niloticus fingerlings.

\subsection{Test Animal}

\section{Materials And Method}

Oreochromis niloticus (Nile Tilapia, Gnathastomata, Cichlidae) fingerlings of similar sizes (mean snout to tail; $11 \pm 6 \mathrm{~cm}$, mean weight; $20 \pm 4 \mathrm{~g}$ and age (4 - 6 weeks old) were purchased from Agboola farms and transported to the laboratory in 25 litre Jerry cans to holding tanks $(50$ X $30 \times 35 \mathrm{~cm})$, which contained water from fish pond (opened at the top for aeration) in the laboratory. The fingerlings were kept in the holding plastic tanks, half filled (15 litres) with dechlorinated tap water, to acclimatize to laboratory conditions $\left(28 \pm 2{ }^{0} \mathrm{C}, \mathrm{R} . \mathrm{H}\right.$ $70 \pm 2 \%$ ) for a period of 7 days before they were used in the bioassays. The fingerlings were fed with fish food (Coppens), and the water was changed once every $48 \mathrm{hrs}$, aerated continuously with Cosmo air pump (Double type 1200). Circular plastic bowls (volume $=5$ liters, bottom diameter $=18 \mathrm{~cm}$ ) were used as bioassay container.

\subsection{Test Chemicals}

The heavy metal investigated in this work was obtained as metallic salts of Fisons laboratory reagents, analar grades (molecular weight $249.68 \mathrm{~g}$ ) of copper as $\mathrm{CuSO}_{4} .5 \mathrm{H}_{2} \mathrm{O}$ purity; 98.5-101\%. The choice of heavy metal for this study was based on the available, common and abundant metal from the results of a chemical survey of industrial effluents that empty into the Lagos lagoon (3)

\subsection{Preparation of Media of Varying Salinities}

Sea water was obtained in 25 litres plastic Jerry cans from Alpha beach Lekki, Lagos state, and taken to the laboratory, where the salinity was measured with a salinometer. On the basis of salinity level, computed amounts of the seawater were measured out and mixed with dechlorinated tap water to obtain water solutions at pre-determined salinity levels. The salinity of the prepared media was retested with a salinometer for more accurate determination of the salinity which was recorded and used in appropriate experiments.

\subsection{Preparation of Test Media}

A pre-determined amount of each heavy metal compound was weighed (using an oertling 30TD top loading balance) and diluted with given volume of dechlorinate tapwater to obtain a stock solution of known strength. The resultant stock solution was serially diluted to obtain solutions of required concentrations. Actual 
concentration of copper ions in each solution of known strength can be computed based on molecular weight of test compound. Test media were always made up to 2 litres because preliminary studies showed that 10 fingerlings survived well in 2 litres of media for a period of 7 days without aeration.

\subsection{Quantal Response (Mortality)}

Fingerlings were taken to be dead if no body movements including the operculum were observed, even when prodded with a blunt glass rod and submerged in water.

\subsection{Salinity tolerance of $O$. niloticus}

Five active fingerlings of similar age and size (as described above) were taken from plastic holding tanks with a sieve and randomly assigned to bioassay containers already holding test media at varying salinities as described below. Each treatment was replicated twice, giving a total of 10 fingerlings that were exposed per salinity level and fresh water. Mortality was assessed as described above, once every $24 \mathrm{hrs}$ for a period of 7 days.

Fingerlings were exposed to salinities of $35,32,22,18,12,2 \mathrm{ppt}$ and fresh water.

\subsection{Relative Acute Toxicity of Test Heavy Metal against O. niloticus}

Five active fingerlings of similar age and size (as described above) were taken from plastic holding tanks with a $200 \mu \mathrm{m}$ sieve and randomly assigned to bioassay containers already holding test media treated with test compound or untreated control as described below. Each treatment was replicated twice, giving a total of 10 fingerlings that were exposed per treatment. Mortality was assessed as described above, once every 24 hrs for a period of 4 days.

\subsection{Acute Toxicity Concentrations}

Acute toxicity concentrations under which relative acute toxicity of test heavy metal against $O$. niloticus was investigated were as follows:

In fresh water

$\mathrm{Cu}\left(\mathrm{CuSO}_{4} .5 \mathrm{H}_{2} \mathrm{O}\right)$ against fingerlings at; 1.0, 2.0, 4.0, 6.0, 8.0, $10.0 \mathrm{mg} / \mathrm{l}$ and untreated control

At salinity of 2 ppt

$\mathrm{Cu}\left(\mathrm{CuSO}_{4} .5 \mathrm{H}_{2} \mathrm{O}\right)$ against fingerlings at; 8.0, 10.0, 12.0, 13.5, $15.0 \mathrm{mg} / \mathrm{l}$ and untreated control

At salinity of 12 ppt

$\mathrm{Cu}\left(\mathrm{CuSO}_{4} .5 \mathrm{H}_{2} \mathrm{O}\right)$ against fingerlings at; 16.0, 20.0, 22.0, 25.0, 28.0, 30.0, $40.0 \mathrm{mg} / \mathrm{l}$ and untreated control

At salinity of 18 ppt

$\mathrm{Cu}\left(\mathrm{CuSO}_{4} .5 \mathrm{H}_{2} \mathrm{O}\right)$ against fingerlings at; 12.0, 16.0, 20.0, 24.0, 28.0, $30.0 \mathrm{mg} / \mathrm{l}$ and untreated control

\subsection{Statistics}

The dose response data for freshwater and varying salinities were analyzed by probit analysis after (18). Indices of measuring toxicity $\left(\mathrm{LC}_{95}, \mathrm{LC}_{50}, \mathrm{LC}_{5}\right)$ and their $95 \%$ confidence limits were employed.

\subsection{Salinity Tolerance of $O$. niloticus}

\section{Results}

Based on mortality assessment, $O$. niloticus could not survive for any appreciable period in media with salinity higher than $22 \mathrm{ppt}$ (Fig. 1). In media with salinity of $18 \mathrm{ppt}$, between $50-60 \%$ mortality was recorded in $48 \mathrm{hrs}$ but mortality stabilized at $70 \%$ after $72 \mathrm{hrs}$, for the reminder of the exposure period ( 7 days). At 2 and 12 ppt, mortality occurred at low levels, but stabilized at $30 \%$ after 72 hrs (Fig. 1). No mortality was recorded in fingerlings exposed to media with fresh water.

\subsection{Influence of Salinity on the Acute Toxicity of Copper Sulphate against O. niloticus}

The toxicity of $\mathrm{CuSO}_{4}$ increased with increasing or decreasing salinity, beyond $12 \mathrm{ppt}$, where it was minimal. Based on $96 \mathrm{hr} \mathrm{LC}{ }_{50}$ values, the toxicity of $\mathrm{CuSO}_{4}$ against $O$. niloticus was $27.785 \mathrm{mg} / 1$ at $12 \mathrm{ppt}$, as against $2.492 \mathrm{mg} / 1$ and $10.008 \mathrm{mg} / \mathrm{l}$ at freshwater and 2ppt respectively, and also as against $16.786 \mathrm{mg} / 1$ at $18 \mathrm{ppt}$ (Fig. 2)

Relative toxicity of $\mathrm{CuSO}_{4}$ based on $24,48,72$ and $96 \mathrm{hrs}^{2} \mathrm{LC}_{50}$ values also followed a similar trend as observed with the $96 \mathrm{hr} \mathrm{LC} \mathrm{L}_{50}$ values in all media. There was no overlap in $95 \%$ confidence limit for $96 \mathrm{hr} \mathrm{LC}_{50}$ values for all media. Figs. 3 and 4 displaying the Probit line graphs of the toxicity data for the test freshwater fish species under varying salinity conditions. 


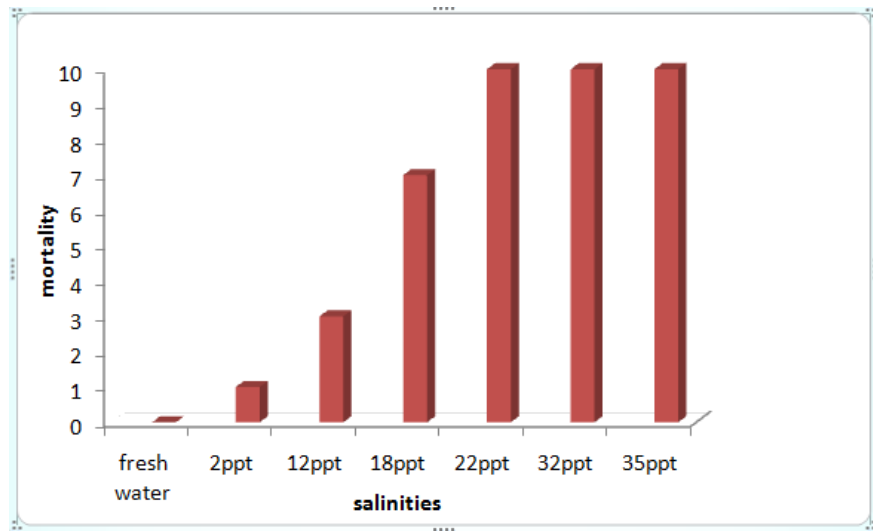

Figure 1: Salinity Tolerance of $O$. niloticus

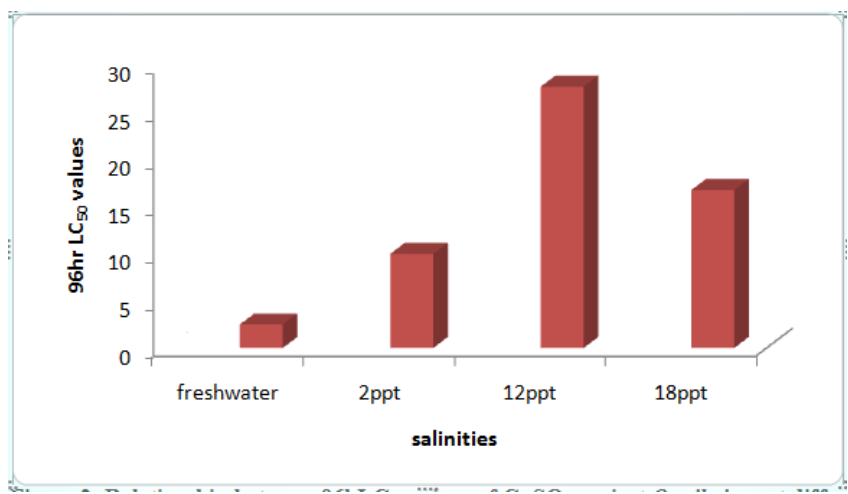

Figure 2: Relationship between $96 \mathrm{hLC}_{50}$ values of $\mathrm{CuSO}_{4}$ against $O$. niloticus at different salinities

Relative toxicity of $\mathrm{CuSO}_{4}$ based on 24, 48, 72 and $96 \mathrm{hrs} \mathrm{LC}_{50}$ values also followed a similar trend as observed with the $96 \mathrm{hr} \mathrm{LC} \mathrm{L}_{50}$ values in all media. There was no overlap in $95 \%$ confidence limit for $96 \mathrm{hr} \mathrm{LC}_{50}$ values for all media. Figures 3, 4, 5 and 6 displayed the Probit line graphs of the toxicity data for the test freshwater fish species under varying salinity conditions.

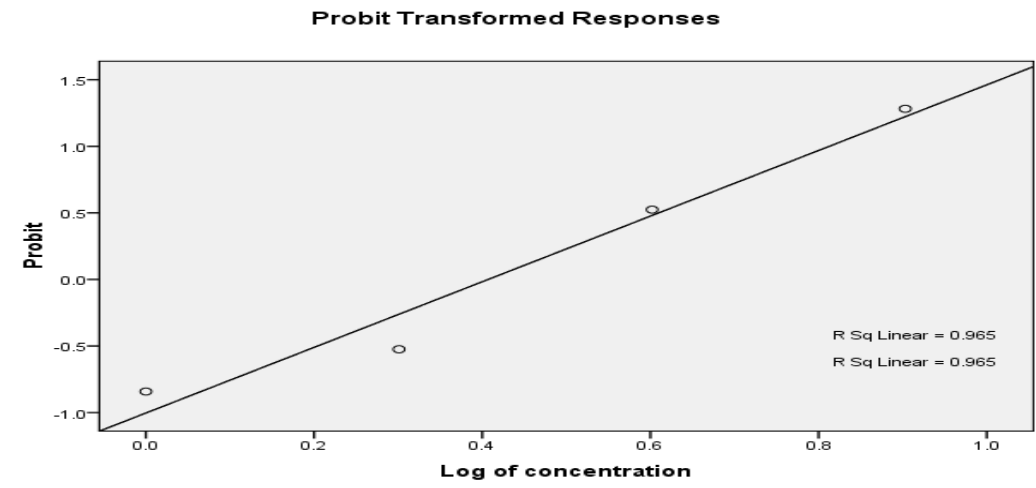

Figure 3: Probit Line Graph of Cuso4 against Oreochromis Niloticus in Fresh Water.

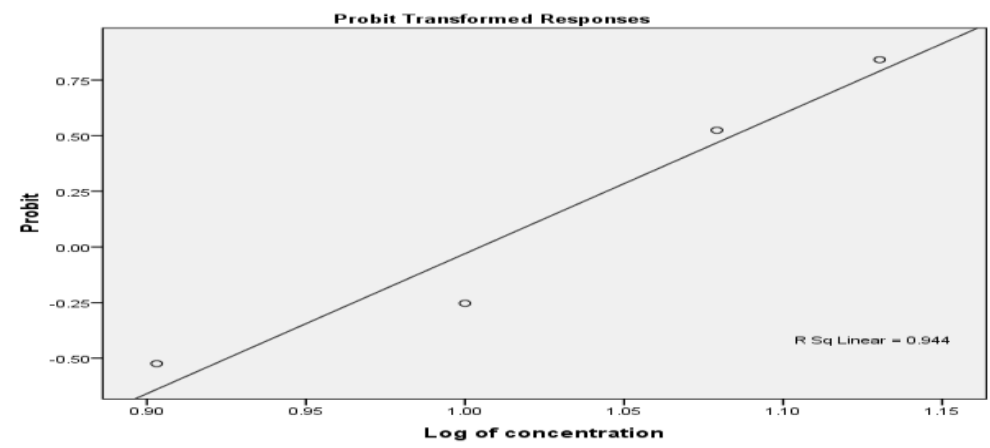

Figure 4: Probit Line Graph of Cuso4 against Oreochromis niloticus 2 ppt. 


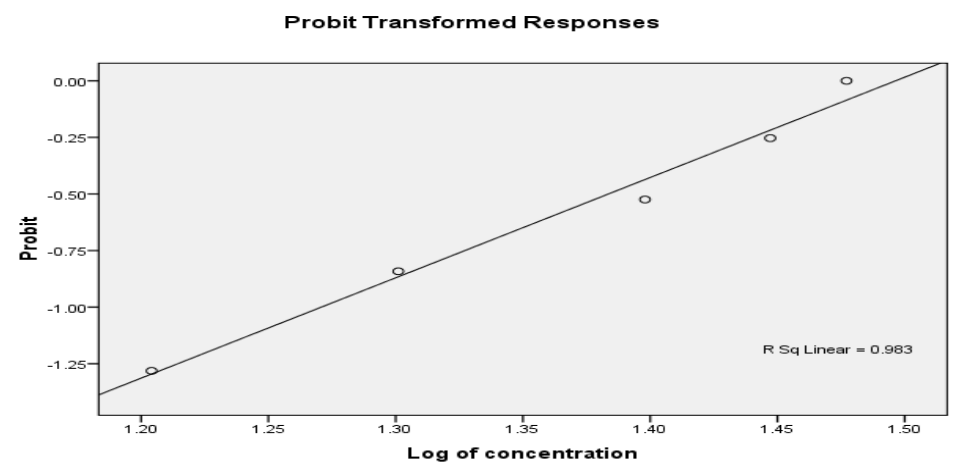

Figure 5: Probit Line Graph of CuSO4 against Oreochromis niloticus 12 ppt.

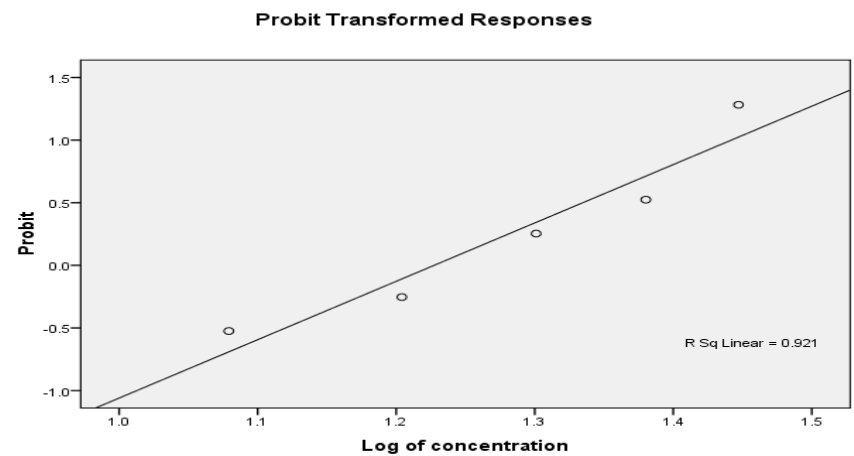

Figure 6: Probit Line Graph of CuSO4 against Oreochromis niloticus 18 ppt

\section{Discussion}

Results obtained from this study showed that $O$. niloticus fingerlings are not able to tolerate salinity above 22ppt, but do well at lower salinities as well as freshwater. This is in agreement with the findings of (19) that studied the life and biology of $O$. niloticus and reported that the fish can survive in waters with salinity between $0-15 \mathrm{ppt}$, but the optimum salinity range for the fish is $10-15$ ppt. One major innate characteristic that contributes to the success of this species is their form of osmoregulation. Euryhaline species, like O. niloticus, carry out hyper-hypo osmoregulation. They switch from hyper osmoregulation to hypo osmoregulation and vice verse during variations in salt content of water in their habitat, but variations tending towards the extremities may result in stress or death, as was demonstrated with this fish at extremely high salinities in this work.

This study has also shown that salinity influenced the toxicity of $\mathrm{CuSO}_{4}$ against $O$. niloticus fingerlings. It is interesting to note that $\mathrm{CuSO}_{4}$ was most toxic to the fish at freshwater, contrary to expectations that since bred under freshwater conditions, they will show more tolerance to the metal in fresh water. This is in agreement with findings of Oyewo (3) who showed that other similar brackish water adapted bony fishes such as Tilapia guinensis and Nerite senegalensis were known to be most susceptible to heavy metal pollutants including $\mathrm{CuSO}_{4}$ at salinities tending towards the extremities (below $5 \mathrm{ppt}$ and above $25 \mathrm{ppt}$ ), but were several folds more tolerant at salinities of up to $15 \mathrm{ppt}$ which falls within typical brackish water salinity (10-20 ppt).

The Probit line graphs of the toxicity data for the O. niloticus test under varying concentrations of $\mathrm{CuSO}_{4}$ shows a corresponding increase in mortality response with increased exposure and time. This shows the acute toxicity of copper which is in agreement with the research of $(20,21,22)$

The practical significance of this study is in setting ecologically sound safe limits for discharge of heavy metals into the lagoon ecosystems, aimed at protecting brackish water organisms, data used should be based on those obtained from studies carried out over a wide range of salinity conditions, tending towards the extremes which occur during peak periods of the hydrological seasons (wet and dry). Additionally, for aquaculture purposes, it may be better to breed $O$. niloticus in water with salinities which falls within the range of that which occur in its natural habitat (10-20 ppt) for most part of the year, except for the peak periods of the two seasons (wet and dry). This will ensure an increase in tolerance of the fish to pollution, especially that imposed by heavy metals. 


\section{Conclusion}

Setting safe limits for $O$. niloticus using field data will confer a wider range of protecting the fish when they are breed in fresh water. It can thus be deduced from the study that breeding $O$. niloticus at salinity below 12 ppt will have a higher survival chance especially during acclimatization for laboratory studies.

\section{Acknowledgement}

The authors are grateful to the staff of the analytical Laboratory, University of Lagos for analysis of samples and to Dr Ade-ademilua and Dr Igwo - Ezikpe for reviewing the manuscript.

\section{References}

[1] M. B. Hill, and J. E. Webb, The ecology of Lagos Lagoon II. The Topography and Physical features of Lagos Harbour and Lagos Lagoon. Philosophical Transaction of the Royal Society. Bill. 241, 1958, 319-333.

[2] F.E. Ajagbe, A.O. Osibona, and A.A Otitoloju, Diversity of Edible Fishes of the Lagos Lagoon Nigeria and the Public Health Concerns Based on their Lead $(\mathrm{Pb})$ content. International Journal of Fisheries and Aquaculture. 2(3), 2012, 55-62.

[3] E. O. Oyewo, Industrial Sources and Distribution of Heavy Metal in Lagos Lagoon and their Biological Effects on Estuarine Animals.doctoral dissertion, University of Lagos. 1998.

[4] E.A.Ajao, and S.O.Fagade, A Study of Sediments and Communities in Lagos Lagoon, Nigeria. Oil and Chemical Pollution, 7, 1991, $85-117$.

[5] A. O. Eruola, G. C. Ufoegbune, Z. O. Ojekunle, A. A. Makinde, and I. O. Ogunyemi, (). Analytical Investigation of Pollutants in Lagos Coastal Waters, Nigeria. Advances in Analytical Chemistry, 1(1), 2011,8-11.

[6] E.O. Oyewo, and K.N. Don-Pedro, The Toxicity Ranking Of Four Heavy Metals of Industrial Sources to Six Resident Animals of a Tropical Estuarine Lagoon. Toxicology and Environmental Chemistry, 83(1-4), 2002 87-97.

[7] K. Devagi, and A. Arfiziah, Accumulation and Depuration of Lead and Chromium Using Nerita Lineate. World Applied Science Journal, 6(9), 2009, 1205-1208.

[8] L.D. Chukwu, Studies of Heavy Metal Contamination of Water, Sediment and Decapods Crustaceans from River Sasa. doctoral dissertation University of Lagos. 1991.

[9] A.A. Otitoloju, and K.N. Don-Pedro, Bioaccumulation of Heavy Metals (Zn, Pb, Cu and Cd) by Tympanotonus fuscatus var. radula (L) exposed to sublethal Concentrations of the Test metal Compounds in Laboratory Bioassay. West African Journal of Applied Ecology, 3 2002, 17-29.

[10] A.A. Otitoloju, and K. N. Don-Pedro, Integrated Laboratory and Field Assessments of Heavy Metals Accumulation in Edible Periwinkle, Tympanotonus fuscatus var. radula (L). Ecotoxicology and Environmental Safety. 57(3), 2004, $354-362$.

[11] US EPA, Wildlife Exposure Factor Handbook. Vol 1 EPA/600/R-93/187a, 1993.

[12] M.T. Horne, and W.A. Dunson, Effects of Low Ph, Metals and Water Hardness on Larval Amphibians. Archives of Environmental Contamination and Toxicology, 29, 1995, 500-505.

[13] A. A. Otitoloju, and K. N. Don Pedro, Establishment of the Toxicity Ranking Order of Heavy Metals and Sensitivity Scale of Benthic Animals Inhabiting Lagos Lagoon. West African Journal of Applied Ecology, 3, 2002, 31-41.

[14] S. A. Gerlach, Marine Pollution, Diagnosis and Therapy. (Springer Verlag, Berlin. 1981)

[15] E.O. Lawson, Physic-Chemical Parameters and Heavy Metal Contents of Water From The Mangrove Swamps Of Lagos Lagoon, Lagos, Nigeria. Advances in Biological Research. 5(1), 2011, 08-21.

[16] M. K. Ladipo, V. O. Ajibola, and Oniye, S. J. (). Seasonal Variations in Physicochemical Properties of Water in some Selected Locations of the Lagos Lagoon. Science World Journal, 6 (4), 2011, 1597- 6343.

[17] I.Riba, T.A. Delvallo, J.M. Fotja, and Gómez-Parra, A. The Influence of PH and Salinity on the Toxicity of Heavy Metals in sediment to the Estuarine Clam-Ruditepes philippinarum. Journal of Environmental Toxicology and Chemistry, 23, 2006, 11001107.

[18] D. J. Finney, Probit Analysis. $3^{\text {rd }}$ Edition University Press, London. 1971

[19] P.Thomas, and M. Masser, Tilapia, Life History and Biology. Southern Regional Aquaculture Centre, Publication, $1999,283$.

[20] R. Eisler, Copper Hazards to Fish, Wildlife, and Invertebrates: A Synoptic Review. Biological Science Report USGS /BRD/BRS1998, 1997-0002.

[21] A.A. Otitoloju, Joint action toxicity of heavy metals and their bioaccumulation by benthic animals in the Lagos lagoon, doctoral dissertation, University of Lagos, 2001.

[22] K. Safina, and J. Muhammed, Evaluation of Acute Toxicity of copper to Four Fresh Water fish species. International Journal of Agriculture and Biology. 14(5), 2012, 801-804. 